\title{
Relationship between Crystalline Structure and Mechanical Behavior in Isotropic and Oriented Polyamide 6
}

Nadya Dencheva ${ }^{1}$, Zlatan Denchev $^{1 *}$, M. Jovita Oliveira ${ }^{1}$, Sérgio S. Funari ${ }^{2}$

${ }^{I} I P C$ - Institute for Polymers and Composites, Department of Polymer Engineering, University of Minho, 4800-058 Guimarães, Portugal

${ }^{2}$ HASYLAB at DESY, Notkestraße 85, 22603 Hamburg, Germany

${ }^{*}$ To whom correspondence should be addressed. E-mail: denchev@dep.uminho.pt 


\begin{abstract}
Polyamide 6 (PA6) isotropic films and oriented cables were prepared by compression molding or by consecutive extrusion and cold drawing. These samples were isothermally annealed in the $120-200^{\circ} \mathrm{C}$ range and than subjected to tensile tests at room temperature. Synchrotron wide- (WAXS) and small-angle X-ray scattering (SAXS) patterns were obtained before and after mechanical failure. These data were related with the mechanical properties of the respective PA6 samples. Annealing of isotropic PA6 resulted in an increase of the Young modulus and yield stress values, which was attributed to the observed proportional reduction of the d-spacings of the inter-sheet distances in both $\alpha$ and $\gamma$-PA6 polymorphs. Analysis of the WAXS and SAXS patterns of isotropic PA6 after break allowed the supposition of structural changes in the amorphous phase, being better pronounced with the increase of annealing temperature making the samples less ductile. In oriented PA6 samples annealing resulted in a drastic increase of Young moduli and yield stresses accompanied by phase transition from $\gamma$ - to $\alpha$ - PA6 and well-pronounced reduction of the inter-sheet distances of both polymorphs. Stretching the oriented samples led to an additional $\gamma$-to $\alpha$-transition whose extent was also related with structural changes in the amorphous phase.
\end{abstract}

Key Words: polyamide 6, synchrotron WAXS and SAXS, mechanical properties, polymorphism. 


\section{INTRODUCTION}

Of all n-polyamides currently known and manufactured on an industrial scale, polyamide 6 (PA6) has achieved the widest commercial use and is the best studied. Processing of PA6 may be divided into three broad categories: melt spinning, extrusion and injection molding. The end products are various types of yarns, films, sheets, rods, tubes, coatings of electric conduits etc ${ }^{1}$. A recent application of PA6 is as reinforcing component in what was called "microfibrillar in-situ composites" (MFC) $)^{2,3}$. All of these processing techniques comprise controlled heat- and/or mechanical treatments that have an important impact on the PA6 crystalline structure and hence on its mechanical properties.

While there is a large amount of studies relating the structure or the properties of PA6 to the conditions of its orientation and annealing, relatively few works have been published so far on the relationship between mechanical properties and crystalline structure. Galeski et al studied the mechanisms of deformation of PA6 in uniaxial extension by means of X-ray, microscopy and calorimetric techniques ${ }^{4}$. Stretching of PA6 reportedly led to orientation of the $\alpha$ - and $\gamma$-crystals with macromolecular chains parallel to the drawing direction (DD). It was also demonstrated that the $\alpha$-phase experienced a larger amount of breakdown between the planes determined by the hydrogen bonds, as compared to the $\gamma$-phase. In plane strain compression mode, the same authors ${ }^{5}$ observed shareinduced $\alpha$ - to $\gamma$-transition creating small amounts of $\gamma$-polymorph in the originally all- $\alpha$ form crystalline phase. The latter underwent extensive deterioration by a chain-slip mechanism along the (002) planes containing the hydrogen bonds.

More recently, Lin and Argon performed extensive structural and mechanical investigations on the plastic deformation in PA6 by means of X-ray scattering and electron microscopy ${ }^{6}$. Quasi-single crystal PA6 samples were prepared by plain-strain compression at elevated temperature in a channel die. Investigation of the crystallographic slip 
processes confirmed the conclusion that in the more stable $\alpha$-form the (002) planes of the H-bonded sheets constituted the main active slip system. The same authors represented an interesting analysis of the crystal slip thermal activation ${ }^{7}$.

Ito and $\mathrm{al}^{8}$ investigated the effects of PA6 $\alpha$ - and $\gamma$-crystalline forms on the deformation behavior. The $\alpha$-PA6 crystals were obtained from solution or melt at ordinary crystallization conditions. The $\alpha$-phase was converted into $\gamma$-form by iodine treatment. Wide- and small-angle X-ray scattering (WAXS, SAXS) techniques were employed for structural characterization, and dynamic mechanical analysis - to study mechanical properties. The general conclusion was that the $\gamma$-form was more ductile than the $\alpha$-form. However, the authors did not elucidate the potential influence upon ductility of the profound chemical changes of the $\gamma$-PA6 phase studied.

The mechanical behavior and structural evolution upon uniaxial and biaxial drawing above the glass-transition temperature $\left(T_{g}\right)$ of PA6 films was studied in detail by PenelPierron et al by means of WAXS, infrared spectroscopy and differential scanning calorimetry ${ }^{9}$. The authors observed a higher ductility of PA6 in what they called mesomorphic $\beta$-form, as compared to samples in $\gamma$ - and $\alpha$ - form. Under uniaxial drawing, a greater part of the $\beta$-phase was shown to undergo strain-induced transition into $\alpha$-PA6, the latter being more pronounced above $120^{\circ} \mathrm{C}$. The $\gamma$-phase, which was thermally stable up to $200^{\circ} \mathrm{C}$, also transformed into $\alpha$-PA6. A structural explanation for the improved ability of PA6 for biaxial orientation at temperatures below $120^{\circ} \mathrm{C}$ was presented. It was related to the $\beta \rightarrow \alpha$ phase reorganization at higher temperatures accompanied by a collapse of the van der Waals interactions between the sheets leading to sample splitting under normal stress component.

The present article is a part of a broader study on the structure-properties relationship in in-situ composite materials based on polymer blends containing polyamides. It reports 
on the mutual relationship between the crystalline structure and the mechanical behavior in well-characterized, oriented or isotropic PA6 samples containing different amounts of $\alpha$ and $\gamma$-polymorphs. The main goal of this work is twofold: (i) to investigate the influence of the starting structure (i.e., degree of crystallinity, content of $\alpha$ - and $\gamma$-polymorphs and orientation) upon the mechanical properties of the samples, e.g., Young modulus, yield stress and elongation, stress and elongation at break; (ii) to elucidate the impact of strain on the crystalline structure after sample failure considering the changes in the crystalline phase. For this purpose, synchrotron WAXS and SAXS patterns were obtained before and after mechanical failure of various PA6 samples and processed so as to extract information related to the crystallinity, d-spacings, long spacings and phase transitions. An attempt was made to associate the WAXS and SAXS structural data with the mechanical properties of the samples.

\section{EXPERIMENTAL}

\section{Materials and Sample Preparation}

Ultramid B35 (BASF, Germany) - a medium-viscosity, general purpose polycaproamide grade with a melting temperature $T_{m}$ of $220^{\circ} \mathrm{C}$ (DSC) obtained by ring-opening polymerization was used as a starting material. Two types of samples were prepared and studied. The first one designated as "PA6 film" was obtained by compression molding of as-supplied granules, preliminary dried for 5 hours at $90^{\circ} \mathrm{C}$. The starting material was pressed at $250^{\circ} \mathrm{C}$ and pressure of 6 tons applied for $5 \mathrm{~min}$, followed by isothermal crystallization for 1 hour at 3 different temperatures $-120^{\circ} \mathrm{C}, 160^{\circ} \mathrm{C}$ or $200^{\circ} \mathrm{C}$. The $200-250$ $\mu \mathrm{m}$-thick films so prepared were cooled to room temperature at a rate of ca. $20^{\circ} \mathrm{C} / \mathrm{min}$. 
Five specimens for tensile stress measurements with $25 \mathrm{~mm}$ length and $4 \mathrm{~mm}$ width were cut out from each film.

The second sample designated as "PA6 oriented cable" was prepared in an extruder line including a Lestritz LSM 30.34 intermeshing co-rotating twin-screw extruder, two water baths, two haul-off units and a winder positioned downstream. The extrusion was performed at a set temperature of $250^{\circ} \mathrm{C}$. The extrudate was cooled in the first water bath down to $12^{\circ} \mathrm{C}$ while drawing it at a draw ratio (DR) of $\lambda=2.6$. The final drawing was performed in the second haul-off unit after heating the stretched cable up to $90-96^{\circ} \mathrm{C}$ in the second water bath. More details about the extruder line can be found elsewhere ${ }^{2}$. The oriented PA6 cables were annealed with free ends at 120,160 or $200^{\circ} \mathrm{C}$ in an oven. Each annealing temperature was reached at heating rates of $10^{\circ} \mathrm{C} / \mathrm{min}$. After 1 hour annealing at the respective temperature, the heating was switched off and the sample was cooled at ca. $10^{\circ} \mathrm{C} / \mathrm{min}$ until returning to room temperature. Five specimens with gauge length of $50 \mathrm{~mm}$ were cut out from each PA6 cable for tensile testing.

\section{WAXS and SAXS Measurements}

Synchrotron radiation with a wavelength of $0.15 \mathrm{~nm}$ generated at the Soft Condensed Matter Beamline (A2) of HASYLAB, Hamburg, Germany was employed. The first setup used permitted two-dimensional (2D) SAXS and 1D WAXS measurements. The sampleto-detector distance for SAXS was set to $2850 \mathrm{~mm}$, the diffraction patterns being registered by means of a MARCCD 2D detector with exposure times between 30 and $90 \mathrm{sec}$. The 1D WAXS profiles were registered by a linear scintillation detector positioned at $240 \mathrm{~mm}$ in respect to the sample holder. In the second setup for 2D WAXS, the linear detector was removed and the MARCCD detector was positioned at $90 \mathrm{~mm}$ from the sample. A specially designed sample holder was used allowing for a controlled heating/cooling of the 
sample in the $25-300^{\circ} \mathrm{C}$ range. A multi-channel process- and program controller was used to regulate the sample temperature in heating or cooling at various rates. The difference between the read-out and real temperature of the sample was found to be $1-2^{\circ} \mathrm{C}$ at a heating or cooling rate of $20^{\circ} \mathrm{C} / \mathrm{min}$.

\section{SAXS and WAXS Data Handling}

Corrections for background scattering, irradiated volume and beam intensity were performed for each image. The 2D SAXS patterns were integrated in the range of $\mathbf{s}$ values between 0 and $0.19 \mathrm{~nm}^{-1}$, $\mathbf{s}$ being the scattering vector, whose modulus is defined as $s=\left(s_{12}^{2}+s_{3}^{2}\right)^{0.5}=(2 / \lambda) \sin \theta$. For all isotropic samples the one-dimensional correlation function (CF) was calculated after Lorentz correction of the raw SAXS profiles as indicated earlier ${ }^{10}$.

The 1D WAXS curves were also corrected for background scattering, irradiated volume and beam intensity. Their scattering angle axis was calibrated using the angular position of the reflections of a standard crystalline poly(ethylene terephthalate) sample. The s-range covered in the WAXS measurements was from 0.3 to $4.8 \mathrm{~nm}^{-1}$. All WAXS curves were fitted with Gaussian peaks. In the case of isotropic PA6 sample the total degree of crystallinity (or, crystallinity index, $\mathrm{CI}$ ) was calculated as a relation of the areas of all crystalline peaks and the total area underneath the WAXS curve:

$$
C I=\frac{\sum A_{c}}{\sum\left(A_{c}+A_{a}\right)}
$$

There, $A_{c}$ is the integrated area underneath the respective crystalline peaks and $A_{a}$ is the integrated area of the amorphous halo.

In PA6 oriented cables, the intensity of the meridional point-like reflections cannot be determined from the 1D WAXS curves. In this case, $\Sigma A_{c}$ in Eq. 1 measures the 
scattering intensity along the equator only, i.e. one can define it as "equatorial crystallinity index" $(\mathrm{ECI})^{10}$.

The 1D WAXS patterns were used also to determine the interplanar spacings $d_{h 00}$ and $d_{00 l}$ using the Bragg's law:

$$
2 d_{h k l} \sin \theta_{h k l}=\lambda
$$

Here, $\lambda=1.5 \AA$ is the $\mathrm{X}$-ray wavelength and $\theta$ is the half of the $2 \theta$ position of the center of the respective crystalline peak. The d-spacing of the $(0 \mathrm{k} 0)$ crystalline planes was determined by slicing the meridional point-like reflections of the 2D WAXS patterns of oriented PA6 samples.

\section{Tensile Tests}

Uniaxial tensile tests were performed in an Instron model 4505 tensile test machine. The tests were carried out at $23 \pm 2^{\circ} \mathrm{C}$ with a standard tensile force of $1 \mathrm{kN}$ at constant crosshead speed of $50 \mathrm{~mm} / \mathrm{min}$. The nominal stress was determined as a ratio of the tensile force and the initial cross section of the sample. The nominal strain was determined as a ratio of the sample gauge length at any time during drawing and that prior to drawing.

\section{RESULTS}

\section{Mechanical data}

Figure 1 shows the stress-strain curves of differently annealed isotropic PA6 films (a) and oriented cables (b), respectively. All data extracted from these curves, are presented in Table 1. 
Isotropic PA6 samples display an augmentation (from 40 to $50 \mathrm{MPa}$ ) of the yield stresses as the temperature of annealing increases, accompanied by a statistically significant growth of the E-moduli. At the same time, the strain values drop (Table 1).

The oriented PA6 samples demonstrate different stress-strain curves upon annealing (Figure 1b, Table1). All sample show two yield points, the first being in the range between $66 \mathrm{MPa}$ (cable without annealing) and $105 \mathrm{MPa}\left(1 \mathrm{~h}\right.$ at $\left.160^{\circ} \mathrm{C}\right)$ and the second yield point - between $123 \mathrm{MPa}$ (cable without annealing) and $180 \mathrm{MPa}$ (1h at $200^{\circ} \mathrm{C}$ ). After the second yield point, strain hardening occurs being better observable with the sample without annealing. This same sample showed the biggest strain at break. As with the isotropic films, increasing the annealing temperature led to a significant drop in the strain values, whereby the sample annealed at $200^{\circ} \mathrm{C}$ showed almost brittle failure. At the same time, the E-moduli displayed an increase of more than three times, attaining its maximum of $3.8 \mathrm{GPa}$ for the sample heated at $200^{\circ} \mathrm{C}$ (Table1).

\section{D WAXS}

1D WAXS patterns were obtained of isotropic (Figure 2) and oriented (Figure 3) PA6 samples, initially annealed for $1 \mathrm{~h}$ at different temperatures in the $100-200^{\circ} \mathrm{C}$ range, before and after the tensile test. After fitting the curves as indicated earlier ${ }^{10,11}$, data on the $\alpha$ - and $\gamma$-crystal fractions, as well as of the total crystallinity indexes were obtained (Table 2). It can be seen that in isotropic PA6 samples the $\alpha$-form is the predominant one and that the annealing in the $120-200^{\circ} \mathrm{C}$ range does not change significantly the relation between the two polymorphs. The respective CI values remain between 44-45\%. Stretching until mechanical failure of these samples leads to an increase of the $\alpha$-CI, better expressed for the sample annealed at $120^{\circ} \mathrm{C}$ (by $10 \%$ ). The $\gamma$-crystalline fraction before and after sample failure remains unchanged or drops slightly at the lowest annealing temperature. 
Figure 3 a and Table 2 confirm our previous finding ${ }^{10}$ that oriented PA6 cables obtained by cold drawing to high DR results in a crystalline structure containing more $\gamma$ than $\alpha$-crystalline form - 33 against $12 \%$, respectively. Annealing of such cable in the 120 $160^{\circ} \mathrm{C}$ range decreases $2-5$ times the $\gamma$-phase content, whereas the $\alpha$-type crystallinity grows at a similar rate. After $1 \mathrm{~h}$ at $200^{\circ} \mathrm{C}$ this tendency is inversed decreasing slightly the $\alpha$-phase content. Applying an external tensile stress to the oriented cable without annealing leads to additional transformation of $\gamma$ - to $\alpha$-form. As seen from Table $2, \gamma$-PA6 fraction decreases from 33 to $16 \%$, while the $\alpha$-phase content grows from 12 to $32 \%$. Similar trend is registered with the oriented PA6 samples annealed at 120 and $160^{\circ} \mathrm{C}$. Stressing the sample annealed at $200^{\circ} \mathrm{C}$ displays the inverse transition: the $\gamma$-CI value upon sample failure is with more than $10 \%$ higher than before the tensile test. At the same time, the $\alpha$-CI decreased with $6 \%$.

\section{D SAXS and 2D WAXS Isotropic PA6}

Figure 4 shows the 2D SAXS patterns of differently annealed isotropic PA6 films before (a-c) and after (d-f) mechanical tests. The same figure shows also the 2D WAXS patterns of the respective samples after mechanical failure (g-i). As expected, the SAXS patterns of the samples before mechanical test are non-oriented, of circular symmetry. They show an almost homogeneous distribution of the scattered intensity in the angular region between $-\pi / 2$ and $+\pi / 2$ (Figure 5 , solid symbols). Stretching to mechanical failure has a different effect on the orientation of the SAXS patterns, depending on the temperature of annealing. The sample annealed at $120^{\circ} \mathrm{C}$ that attains the highest strain at break (Fig. 1a) displays an oriented SAXS pattern of fibre symmetry (Fig. 4d). Its azimuthal scan (Fig. 5, $120^{\circ} \mathrm{C}$, open symbols) is a typical example of a four-point scattering diagram with a bimodal distribution of the scattered intensity. There is a strong orientation in the direction of the 
applied stress. Interestingly enough, in the 2D WAXS pattern of this same sample (Fig. 4g) the two Debye rings are with apparent isotropic intensity distribution. Azimuthal scans in the $-\pi /+\pi$ angular region showed an almost isotropic internal ring $(\alpha 200)$ and some week orientation in the external ring $\alpha(002) /(202)$ coinciding with the stretching direction (Figure 6a).

Annealing at $160^{\circ} \mathrm{C}$ makes that stretching of this sample results in much weaker orientation of the 2D SAXS pattern (Fig. 4e) as compared to that of the previous sample. The difference of the azimuthal distribution of the scattered intensity between the initial unstressed and the broken samples is quite small (Figure 5). At the same time, the anisotropy of the $\alpha(002) /(202)$ WAXS refection (Figure 6 b) is significantly stronger than with the broken sample annealed at $120^{\circ} \mathrm{C}$ indicating higher deformation of the crystalline phase. Similar effects are observed with the 2D SAXS and WAXS patterns of the sample annealed at $200^{\circ} \mathrm{C}$ and stretched to break (Fig. $4 \mathrm{f}$ and $4 \mathrm{i}$ ). As seen from the corresponding azimuthal scans in Figure 6, the anisotropy of the two WAXS reflections are basically the same as of the sample annealed at $160^{\circ} \mathrm{C}$. The SAXS pattern after break of the film annealed at $200^{\circ} \mathrm{C}$ is slightly more anisotropic as compared to that of the previous sample (Figure 5).

Table 3 shows the evolution of the long spacing estimates of the isotropic PA6 samples as a function of the initial annealing temperature and the stretching during the mechanical test. In the non-deformed samples, annealing at $200^{\circ} \mathrm{C}$ results in a clear growth of the long spacing values. The latter is due to an increase of the amorphous phase thickness $l_{a}$ to $36 \AA$, the respective values at 120 and $160^{\circ} \mathrm{C}$ being 25 and $26 \AA$. At the same time, the average thickness of the crystalline domains $l_{c}$ remains unchanged (67-68 $\AA$ ). Mechanical failure of the samples annealed at 160 and $200^{\circ} \mathrm{C}$ results in a slight decrease of $l_{c}$ whereas the $l_{a}$ values increase so that the resulting long spacings are slightly 
larger than those before the test. Only the isotropic sample annealed at $120^{\circ} \mathrm{C}$, which after stretching showed an oriented 2D SAXS pattern, displayed a decrease of the long spacing with almost $20 \AA$.

\section{D SAXS and 2D WAXS data oriented PA6}

Table 3 displays also the long spacing values of all oriented cables before and after stretching. The $L_{B}$ values of the oriented cables annealed up to $160^{\circ} \mathrm{C}$ before mechanical test remained relatively constant in the same range of $67-69 \AA$. The cable annealed at $200^{\circ} \mathrm{C}$, however, displays a larger $L_{B}$ of $88 \AA$. Stretching of all cables parallel to their fibre axis until failure resulted in slightly larger long spacings with the exception of the cable annealed at $200^{\circ} \mathrm{C}$ which showed smaller long spacing. All the oriented 2D SAXS patterns were very similar to those in Figure 7 obtained with a cable annealed for $1 \mathrm{~h}$ at $160^{\circ} \mathrm{C}$ before (a) and after tensile test (b). All cables showed typical two-point scattering diagrams with a streak in the central region.

The 2D WAXS patterns of differently annealed PA6 cables taken before and after the tensile test are presented in Figure 8. There, the aforementioned increase of the $\alpha$-form content that occurs as a result of annealing is best noticed in the sample heated for $1 \mathrm{~h}$ at $200^{\circ} \mathrm{C}$ before the tensile test (Fig. $8 \mathrm{~d}$ ), while the cable without annealing showed the most pronounced growth of the $\alpha$ - form content as a result of the tensile test (Fig. 8e). Judging from the differences in the diffracted intensity, the cable without annealing (Fig. 8e) and that annealed at $120^{\circ} \mathrm{C}(8 \mathrm{f})$ suffer serious damages in their crystalline structures caused by stretching. These damages are more evident as compared to those in the cables annealed at 160 and $200^{\circ} \mathrm{C}$ (Fig. $8 \mathrm{~g}$ and $8 \mathrm{~h}$ ). It can be also noticed, that the (020) meridional point-like

reflections of the $\gamma$-PA6 are observable irrespective of the fact that the content of this polymorph strongly decreases as a result of both annealing and stretching (Table 2). The 
(020) reflections were used for calculation of the b-axis of the $\gamma$-phase in all cables (Table 4). The rest of the d-spacings found in Table 4 were extracted from the corresponding 1D WAXS patterns as a function of the annealing temperature and stretching. They will be considered in the Discussion part.

\section{DISCUSSION}

\section{Isotropic PA6 films}

Analyzing the stress-strain curves in Fig. 1a and the numeric data in Table 1, it becomes evident that the higher the annealing temperature, the higher the E-modulus, as well as the yield stress values, the engineering strain at break decreasing from 80 to ca. $40 \%$. At the same time, the X-ray analysis showed that annealing does not change significantly the crystalline structure of the isotropic PA6 films. As seen from Table 2, the $\alpha$-PA6 was the preferable crystalline form independently of the annealing temperature. The $\alpha$-form content varied in the range of $37-39 \%$ whereas the $\gamma$-form content was $6-7 \%$. The data in Table 3 demonstrated that annealing changes neither the long spacings, nor the respective thicknesses of the crystalline and amorphous domains of the isotropic PA6. Only annealing close to the Brill transition point $\left(190-200^{\circ} \mathrm{C}\right)$ results in an increase of the long spacing with about $10 \AA$, which is mainly due to the increase of $l_{a}$ value whereas the $l_{c}$ remains the same. Irrespective of the fact that all the characteristics of the crystalline structure (degree of crystallinity, polymorph type, lamellar and amorphous domain thicknesses) do not change significantly under annealing, the tested PA6 isotropic samples displayed different tensile behaviour. It is known that the changes in the E-modulus and yield stress values can be related to the crystalline phase ${ }^{12}$. The PA6 plasticity in particular was found to be governed by the crystal slip parallel to the H-bonded sheets, i.e. parallel to the (002) crystalline plane in $\alpha$-form and to the (200) crystalline plane in $\gamma$-form, without breaking 
the H-bonds. ${ }^{6,7,9}$ Therefore, the yield stress of PA6 will be controlled, on the crystallographic level, by the inter-sheet distance of the two crystalline forms which corresponds to the d-spacings of the above planes. As seen from Table 4, the inter-sheet distance of the $\alpha$-type crystallite remains lower than that of the $\gamma$-type within the entire annealing temperature range. Moreover, the increase of the annealing temperatures leads to a decrease of the $\mathrm{d}(002)$ of $\alpha$-form from 7,216 to $7.165 \AA$. Although the contribution of the $\gamma$-form is very small (only 6-7 \% from the total CI), the d-spacing of the (200) plane in this polymorph also decreases from $7.675 \AA$ to $7.640 \AA$. As a consequence, the critical resolved shear stress of the main sleep planes in both PA6 polymorphs becomes bigger at higher annealing temperatures, thus contributing to the yield stress growth.

Considering the 2D SAXS patterns in conjunction with the respective 2D WAXS images of the samples after tensile test (Fig. 4 d-f and g-i, respectively) allows a deeper insight into the relation between the structure and the mechanical properties of PA6 isotropic films. The $\alpha$-form content, as well as the total CI of all samples after break increases by $2-10 \%$ being more notable in the sample annealed at $120^{\circ} \mathrm{C}$ (Table 2). Having in mind that the $\gamma$-type crystallinity is almost constant, this increase cannot be due to a phase transition but is probably a result of stress-induced crystallization of amorphous material into $\alpha$-PA6, better expressed with the sample annealed at $120^{\circ} \mathrm{C}$. The same sample displays, after break, high anisotropy of the SAXS pattern along DR and a significant decrease of $L_{B}$ (Fig. 4 d, Fig. $5-120^{\circ} \mathrm{C}$, Table 3). At the same time, in its WAXS pattern the two Debye rings corresponding to the $\alpha(200)$ and $\alpha(002 / 202)$ reflections are entirely isotropic (Figure $4 \mathrm{~g}$ ). Evidently, annealing at $120^{\circ} \mathrm{C}$ results in a quite ductile PA6 film with an amorphous phase susceptible to crystallization. Stretching increases almost twice the $\alpha$ form $/ \gamma$-form proportion (Tab. 2), mainly at the expense of strain-induced crystallization. The amorphous regions are those that bear the stress, whereby a microfibrillar structure is 
formed with such an alignment of the crystalline domains that leads to a decrease of the long spacing values ${ }^{13}$. As seen from Fig. $4 \mathrm{~g}$, these crystalline domains deform very slightly, without changing the almost isotropic distribution of the scattered intensity along the $(\alpha 200)$ or $(\alpha(002 / 202)$ reflection (Fig. 6$)$.

Unlike the PA6 film annealed at $120^{\circ} \mathrm{C}$, the samples treated at 160 and $200^{\circ} \mathrm{C}$ have SAXS patterns after stretching that are much more isotropic (Figure 4e and f; Figure 5), but the WAXS images show more orientation along DR, especially of the outer $\alpha(002 / 202)$ reflection. From the respective 1D WAXS patterns in Figure 2 is also seen that the sample annealed at $200^{\circ} \mathrm{C}$ suffers the strongest changes in its crystalline structure after break. It can be concluded that after annealing at 160 and $200^{\circ} \mathrm{C}$ the external stress applied leads to deformation of the crystalline phase, rather than to deformation of the amorphous phase. It seems that annealing at elevated temperatures provokes a certain "hardening" of the amorphous domains that cannot be accounted for by SAXS and WAXS but affects the deformability of the isotropic PA6. The existence of harder (called also "rigid") amorphous phase in PA6 fibres was proved by ${ }^{13} \mathrm{C}$ and ${ }^{1} \mathrm{H}$ solid-state $\mathrm{NMR}^{14-16}$. Again in PA6 fibres, the presence of oriented fraction in the amorphous phase has been discussed ${ }^{17,18}$. To the best of our knowledge, so far there have been no reports relating the changes in the mechanical properties of isotropic PA6 (e.g, E-moduli, stress and strain values) to alterations in its amorphous structure upon annealing, as suggested in the present study.

\section{Oriented PA6 cables}

The stress-strain curves of all PA6 cables (Fig. 1b) are characterized by double yield, the two yield stresses increasing linearly with the annealing temperature (Table 1). Another observation is the drop of ductility as the annealing temperature increases. The biggest strain at break as well as concomitant strain hardening is displayed by the sample without 
annealing, whereas the PA6 cables annealed above $160^{\circ} \mathrm{C}$ exhibit an almost brittle failure. As to the Young modulus values, they are also affected by the annealing: the higher the temperature, the bigger the Young modulus.

The explanation of the tensile behaviour of the annealed PA6 cables can be related with the alterations in their respective crystalline structure. As seen from Table 2, the preferable crystalline modification for non-annealed cable is the $\gamma$-form. Upon annealing $\gamma$ to $\alpha$-form transition starts, better expressed above $120^{\circ} \mathrm{C}$. The $\alpha$-polymorph becomes the predominant crystalline form for cables annealed between 120 and $200^{\circ} \mathrm{C}$. Table 2 also shows that ECI slightly increases (by 3-5\%), indicating that some formation of $\alpha$-form crystals out of the amorphous material also occurs. The SAXS results showed that the $\gamma$ - to $\alpha$-phase transition and the additional crystallization do not result in alterations of the Bragg's long spacings when the annealing temperature is up to $160^{\circ} \mathrm{C}$ (Table 3). Annealing in the $160-200^{\circ} \mathrm{C}$ range, however, caused a growth of the $L_{B}$ values by approximately $20 \AA$. It was not possible to determine the discrete contribution of the two thicknesses $1_{c}$ and $l_{a}$ to the said growth because the linear CF is not applicable for samples with fibber symmetry. Since the crystallinity index after annealing does not change significantly, the bigger $L_{B}$ after annealing at $200^{\circ} \mathrm{C}$ can hardly be related to $l_{c}$ growth due to lamellar thickening. Moreover, as seen from Table 4, the d-spacings of all planes decrease, meaning that the thermal expansion should also be excluded as a possible reason for the increase of $L_{B}$. It can be supposed, therefore, that some structural changes in the amorphous domains occur during the annealing at $200^{\circ} \mathrm{C}$ and the subsequent cooling down to $30^{\circ} \mathrm{C}$ contributing to the $L_{B}$ change.

We are inclined to consider that the aforementioned $\gamma$-to- $\alpha$ form transition occurring upon annealing is the main reason to the increase of the Young modulus and yield stress. The $\gamma$-PA6 polymorph is shown to be more ductile, while the $\alpha$-polymorph is 
characterized by bigger tensile strength ${ }^{8,9}$. Since with the increase of the annealing temperature $\alpha$-form becomes predominant, it is to be expected that PA6 cables annealed at higher temperature would display bigger yield stresses, as it was the case. From the point of view of crystal slip-governed plasticity, this behaviour can be related to the decrease of the inter-sheet distance in the two crystalline forms when annealed. As it can be seen from Table 4 , the d-spacing of $(002) /(202)$ crystalline plane, which corresponds to the intersheet distance of $\alpha$-form remains smaller than that of the respective plane (200) in $\gamma$-form for each annealing temperature. In addition, the said distance decreases from 7.467 to $7.165 \AA$ for $\alpha$-form and from 7.800 to $7.640 \AA$ for $\gamma$-one when the annealing temperature increases up to $200^{\circ} \mathrm{C}$. Annealing, therefore, as in the case of PA6 isotropic films, increases the critical resolved shear stress of the main slip planes in both $\alpha$ - and $\gamma$ polymorphs of oriented PA6 cable thus leading to the higher yield stresses and E-moduli.

As concerned the appearance of two yield points, it cannot be unambiguously related to the crystal slips occurring in the respective $\gamma$ - and $\alpha$-type crystallites. There will always be a contribution of the amorphous phase, provided that the tensile tests were made at room temperature, i.e. below the $T_{g}$ of the material. The PA6 isotropic films, however, were also tested at room temperature and both $\alpha$ - and $\gamma$-polymorphs were also present. Nevertheless, the respective stress-strain curves showed different behaviour. In our opinion, the observed double yield is more likely related to the appearance of oriented fraction in the amorphous phase, rather than to the presence of two polymorphs. Such oriented fraction was proved in oriented PA6 fibres ${ }^{18}$. One may suppose that the cold drawing used for preparation of the PA6 cables in our case also may generate inhomogeneous amorphous phase that can have an impact on yielding.

The impact of stretching on the structure of PA6 oriented samples is related to a clear, stress-induced $\gamma$ - to- $\alpha$-transition. Interestingly, the latter depends on the annealing 
temperature. Stretching of cables with no annealing or with $1 \mathrm{~h}$ at $120^{\circ} \mathrm{C}$ results in very accentuated phase transition, whereas upon annealing at $160^{\circ} \mathrm{C}$ this trend becomes weaker even inverting if annealing at $200^{\circ} \mathrm{C}$ is applied (Table 2, Fig. 8). One may suppose that the amorphous phase has an important impact upon the phase transitions in the crystalline domains. When it is more flexible, as in the case of cables without annealing or with $1 \mathrm{~h}$ at $120^{\circ} \mathrm{C}$, the stress-induce crystalline modifications are more intense. On the contrary, when there is hardening of the amorphous phase at higher annealing temperatures, this impedes the crystalline phase transitions. Most probably this effect has to do with the effectiveness of the transfer of the external stress to the crystalline domains.

\section{CONCLUSIONS}

The PA6 isotropic films obtained by compression moulding of granules are predominantly in $\alpha$ crystalline form while the $\gamma$-form was the preferable of PA6 cables obtained by extrusion and consequent cold drawing. The annealing applied does not change significantly the crystalline structure of isotropic films but caused $\gamma$-to $\alpha$ form transition in oriented cables. Both isotropic and oriented PA6 showed a growth of the E-moduli and of the yield stresses with increase of the annealing temperature. This behaviour is explained, on crystallographic level, by decrease of the d-spacing of the main crystal-slip planes of two polymorphs after annealing. The external stress applied led to additional $\gamma$-to $\alpha$-form transition in both isotropic and oriented PA6 samples, whereby the higher the annealing temperature, the weaker the inclination to the stress-induced transition. The explanation of this effect was attributed to the possibility of formation of hard fraction (PA6 films) or oriented fraction (PA6 cables) in the amorphous phase. 


\section{Acknowledgements}

This work was supported by the IHP-Contract HPRI-CT-2001-00140 of the European Commission and the HASYLAB Project II-04-047 EC. A partial financial support was provided by FCT project POCI/CTM/57358/2004 N.D. thanks for the financial support of her $\mathrm{PhD}$ research by grant No SFRH/BD/13435/2003 awarded by Fundação para a Ciência e Tecnologia, Portugal.. 


\section{References}

1. Aharoni, S. M. n-Nylons, Their Synthesis, Structure and Properties, John Wiley \& Sons: New York, 1997, p. 316-317

2. Denchev, Z.; Oliveira, M. J.; Carneiro, O. S. J Macromol Sci Part B: Physics 2004, B43, 143

3. Denchev, Z.; Oliveira, M. J.; Mano, J. F.; Viana, J. C.; Funari, S.S. J Macromol Sci Part B: Physics 2004, B43, 163

4. Galeski, A.; Argon, A. S.; Cohen, R. E. Macromolecules 1991, 24, 3945

5. Galeski, A.; Argon, A. S.; Cohen, R. E. Macromolecules 1991, 24, 3953

6. Lin, L; Argon, A. S. Macromolecules 1992, 25, 4011

7. Lin, L; Argon, A. S. Macromolecules 1994, 27, 6903

8. Ito, M.; Mizuochi, K.; Kanamato, T. Polymer 1998, 39, 4593

9. Penel-Pierron, L.; Séguéla, R.; Lefebvre, J.-M.; Miri, V.; Defecher, C.; Jutigny, M.;

Pabiot, J. J Polym Sci Part B: Polym Phys 2001, 39, 1224

10. Dencheva, N.; Nunes, T.; Oliveira, M.J.; Denchev, Z. Polymer 2005, 46, 887

11. Samon, J.M.; Schultz, J.M.; Hsiao, B.S. .Polymer 2000, 41, 2169

12. Schrauwen, B. A. G.; v. Breemen, L. C. A.; Spoelstra, A. B.; Govaert, L. E.; Peters, G. W. M.; Meijer, H. E. Macromolecules 2004, 37, 8618

13. Stribeck, N.; Extraction, representation and interpretation of nanoscale domain structure information from small-angle scattering patterns, Conference on X-ray Investigations of Polymer Structures (XIPS 2001), 5-8 December, 2001 Bielsko Biala, Poland 
14. Schreiber, R.; Veeman, W. S.; Gabriellse, W.; and Arnauts, J. Macromolecules 1999, 32,4647

15. Litvinov, V. M.; Penning, J. P. Macromol Chem Phys 2004, 205, 1721

16. Buda, A.; Demco, D:E.; Bertmer, M.; B. Blu1mich, B.; Litvinov, V.M.; Penning, J.P. J Phys Chem 2003, 107, 5357

17. Murthy, N.S.; Minor, H.; Bednarczyk, C.; Krimm, S. Macromolecules 1993, 26, 1712

18. Murthy, N.S.; Bray, R.G.; Correale, S.T.; Moore, R.A.F. Polymer 1995, 36, 3863 


\section{Figure and Table Captions}

Figure 1 Stress-strain curves of various PA6 samples: (a) isotropic films annealed for 1 hour at 120,160 or $200^{\circ} \mathrm{C}$ and (b) oriented PA6 cables without annealing (w.a.) and annealed at 120,160 and $200^{\circ} \mathrm{C}$ for 1 hour. The curves represented are selected so as to fit best the averaged data in Table 2 .

Figure 2 1D WAXS curves of isotropic PA6 films annealed for1 hour at different temperatures: (a) before and (b) after tensile shear the test

Figure 3 1D WAXS curves of oriented PA6 cables without (w.a.) and with annealing for 1 hour at different temperatures: (a) before and (b) after the tensile test.

Figure 4 2D SAXS patterns of PA6 isotropic films annealed for $1 \mathrm{~h}$ at (a) $120^{\circ} \mathrm{C}$; (b) $160^{\circ} \mathrm{C}$; (c) $200^{\circ} \mathrm{C}$ before tensile test; (d-f) - SAXS patterns of the same samples after test; (g-i) - 2D WAXS patterns of the samples d-f.

Figure 5 Azimuthal scans in the $-1.55-+1.55 \mathrm{CHI}$ region $(\mathrm{rad})$ of the 2D SAXS patterns of differently annealed isotropic PA6 films before (solid symbols) and after (open symbols $)$ mechanical failure $(\mathrm{CHI}=$ azimuthal angle $)$.

Figure 6 Azimuthal scans in the $-1.55-+1.55 \mathrm{CHI}$ region (rad) of 2D WAXS patterns of differently annealed isotropic PA6 films after mechanical failure: (a) for the inner $\alpha(200)$ reflection; (b) for the outer $\alpha(002 / 202)$ reflection.

Figure 7 Typical 2D SAXS patterns of oriented PA6 cables before (a) and after (b) tensile test. Prior to the test, the sample was annealed for $1 \mathrm{~h}$ at $160^{\circ} \mathrm{C}$. 
Figure 8 2D WAXS patterns variously annealed PA6 oriented cables before tensile test: (a) without annealing; (b) $120^{\circ} \mathrm{C}$; (c) $160^{\circ} \mathrm{C}$; (d) $200^{\circ} \mathrm{C}$. WAXS patterns (e-h) are of the respective samples after the tensile test

Table 1 Mechanical properties of isotropic and oriented PA6 samples after various annealing ( $i s o=$ isotropic film; $o c=$ oriented cable). Five standard specimens were analyzed for each sample.

Amendment \#1 ${ }^{*}$ Oriented cables display two yield points.

Table 2 Crystallinity data of variously annealed isotropic and oriented PA6 samples. The numbers in brackets show the respective values after mechanical failure of the corresponding sample. (Note: For the isotropic samples, $\mathrm{CI}_{\text {total }}$ is the total crystallinity index representing the sum of the amounts of the $\alpha$ - and $\gamma$-polymorphs. In oriented samples, ECI accounts for the intensity of the equatorial PA6 reflections leaving out the meridional 020 reflections)

Table 3 Long spacings estimates (L) for differently annealed isotropic and oriented PA6 samples before and after the tensile stress test. In the former case, the average thickness of the crystalline $\left(l_{c}\right)$ and amorphous regions $\left(l_{a}\right)$ are calculated from the linear correlation function $(\mathrm{CR})$.

\section{Amendment \#2}

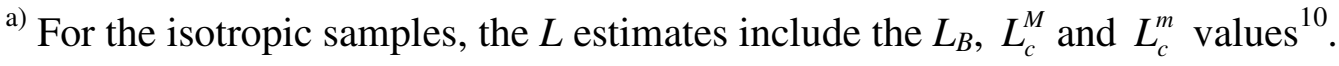

b) For the oriented samples, the $L_{B}$ values are only obtained after Lorentz correction and subtraction of the liquid scattering.

c) Sample does not show coherent SAXS scattering. 
Table 4 Unit cell vectors and the corresponding d-spacings obtained from the 1D WAXS patterns of isotropic and oriented PA6 samples as a function of their initial annealing, before and after the tensile test resulting in sample failure. The $\mathbf{b}$ vector of the $\gamma$-form was obtained from the meridional (020) reflection (Figure 8). 
Figure 1, a; b.
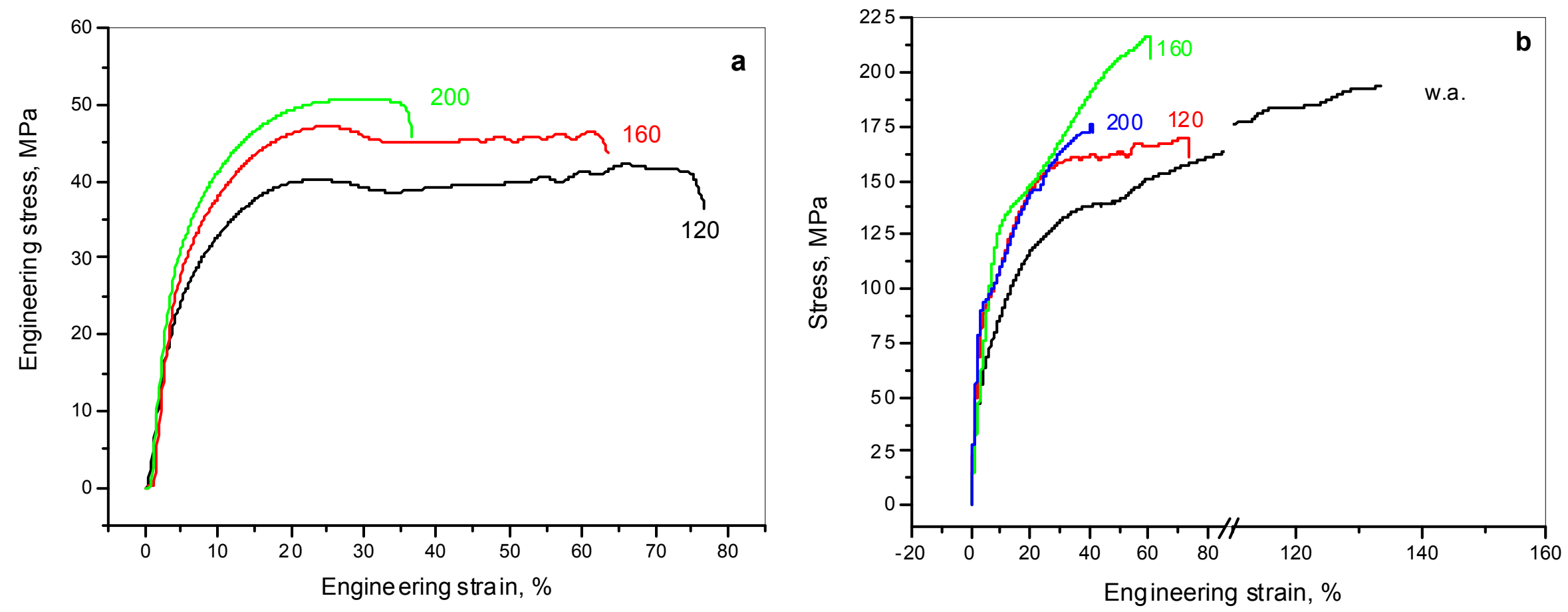
Figure 2, a; b.

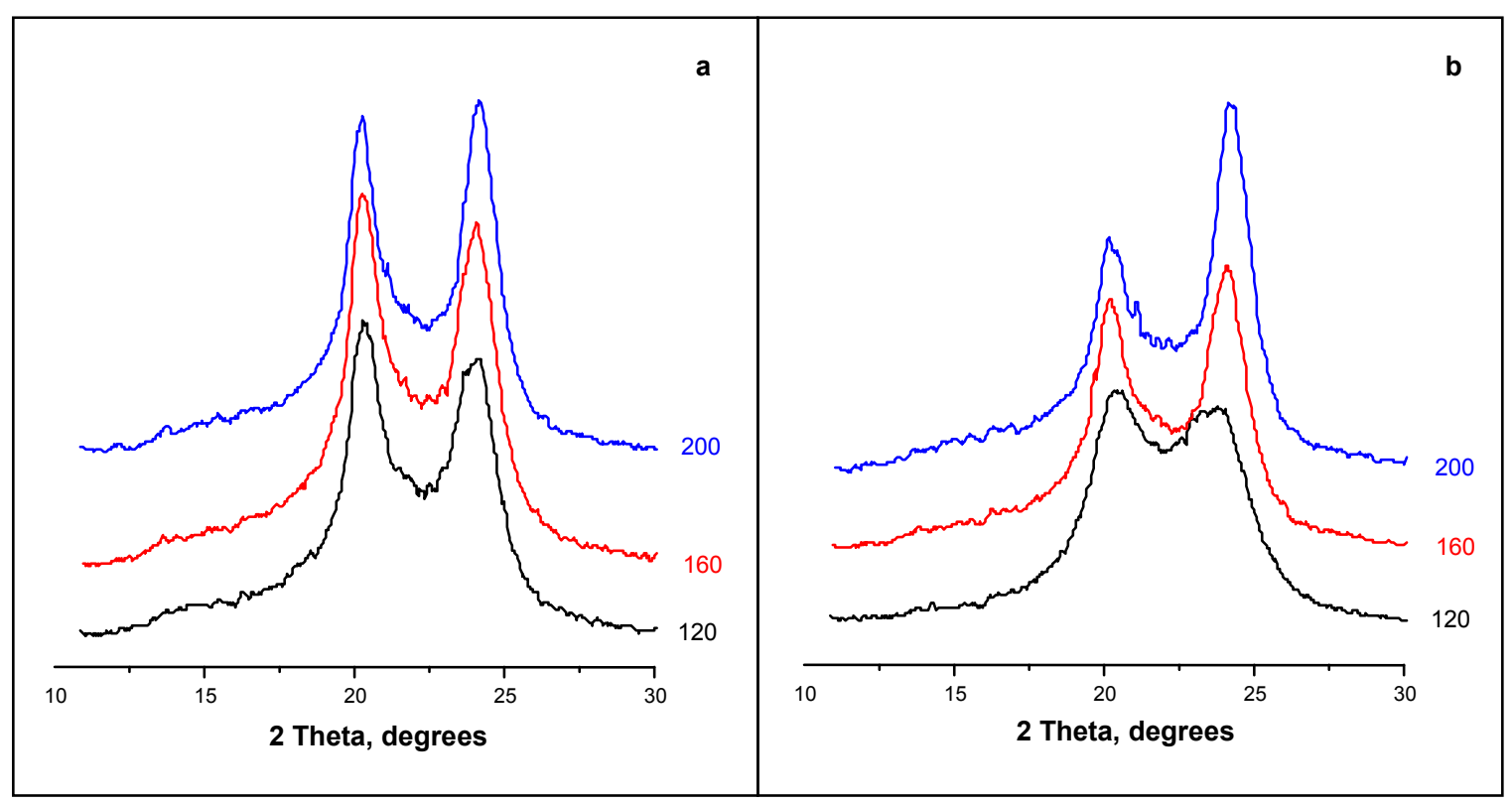


Figure 3, a; b.
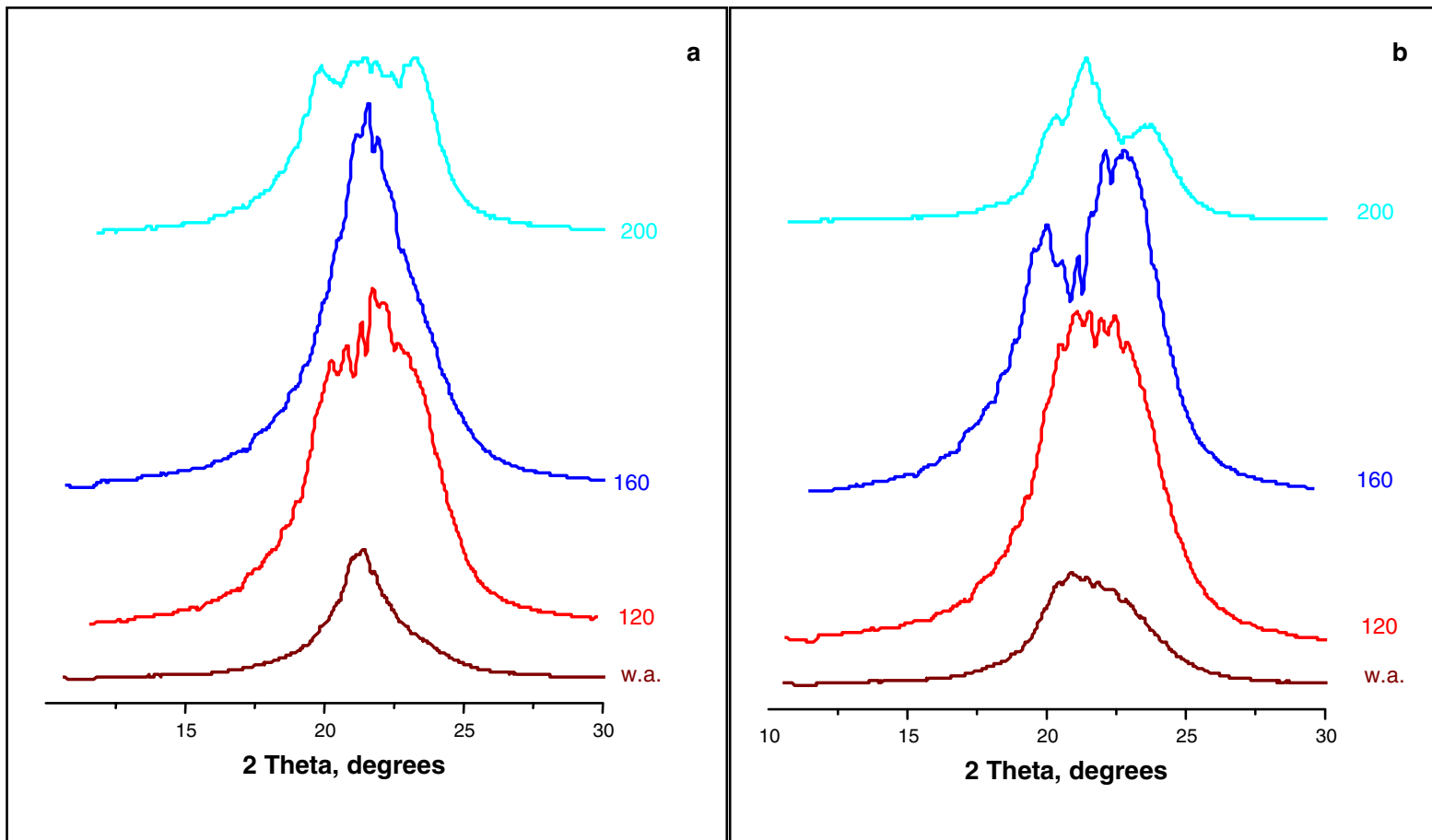
Figure 4, a - i.

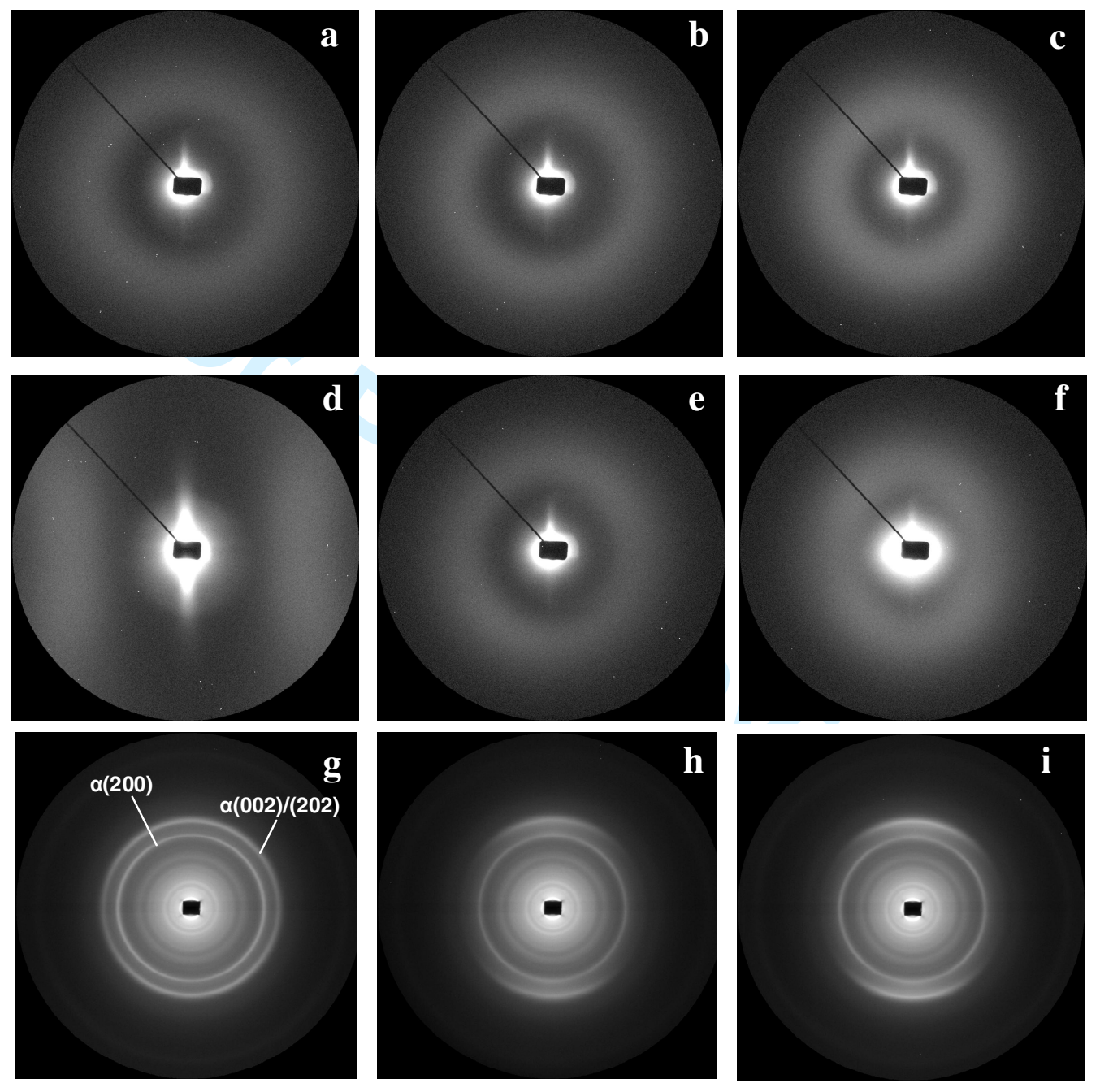


Figure 5.

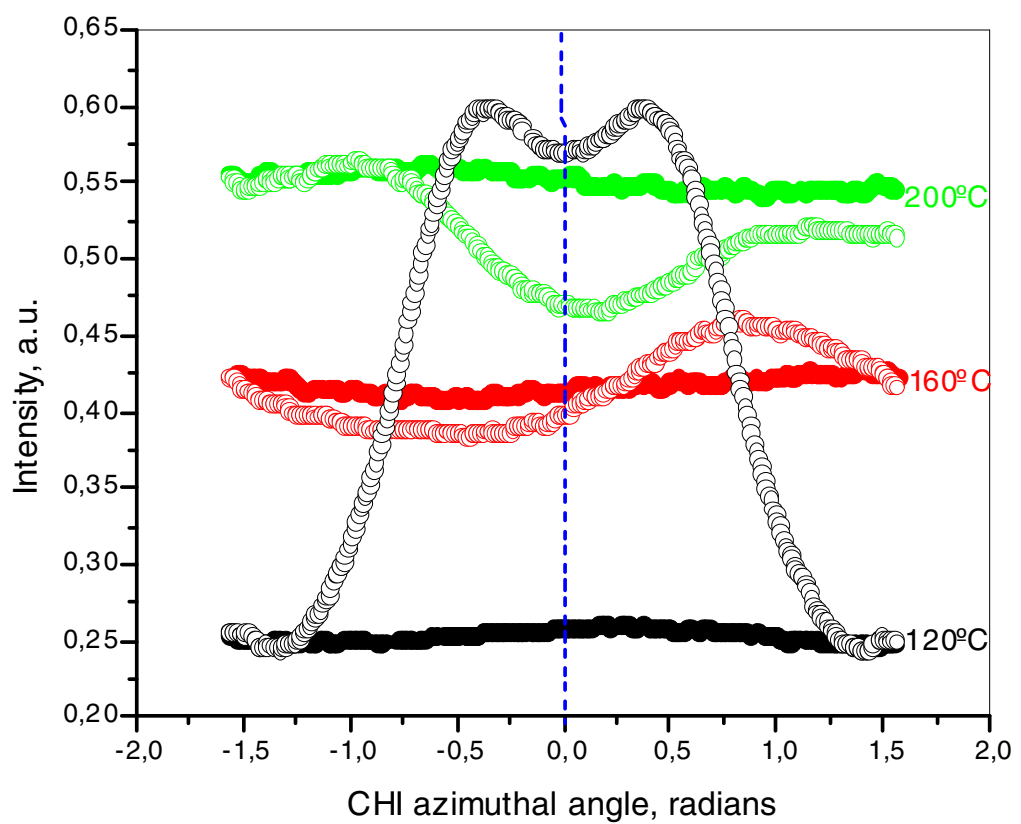


Figure 6, a; b.
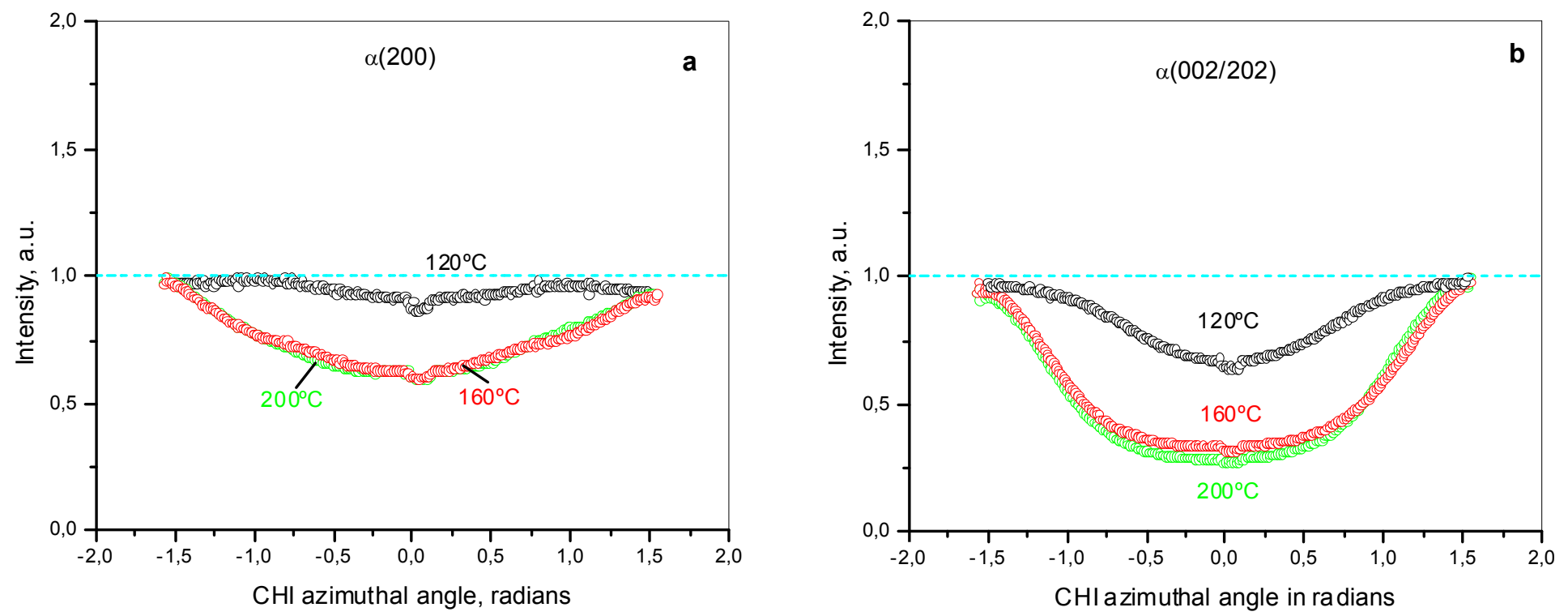
Figure 7, a; b.

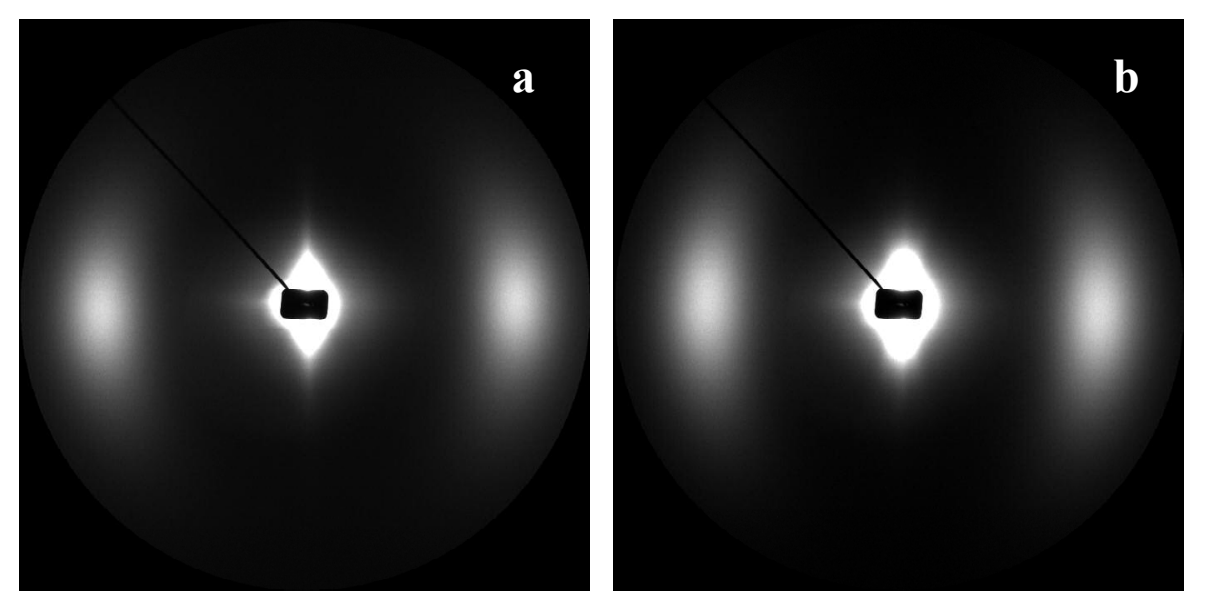


Figure 8, a - h.
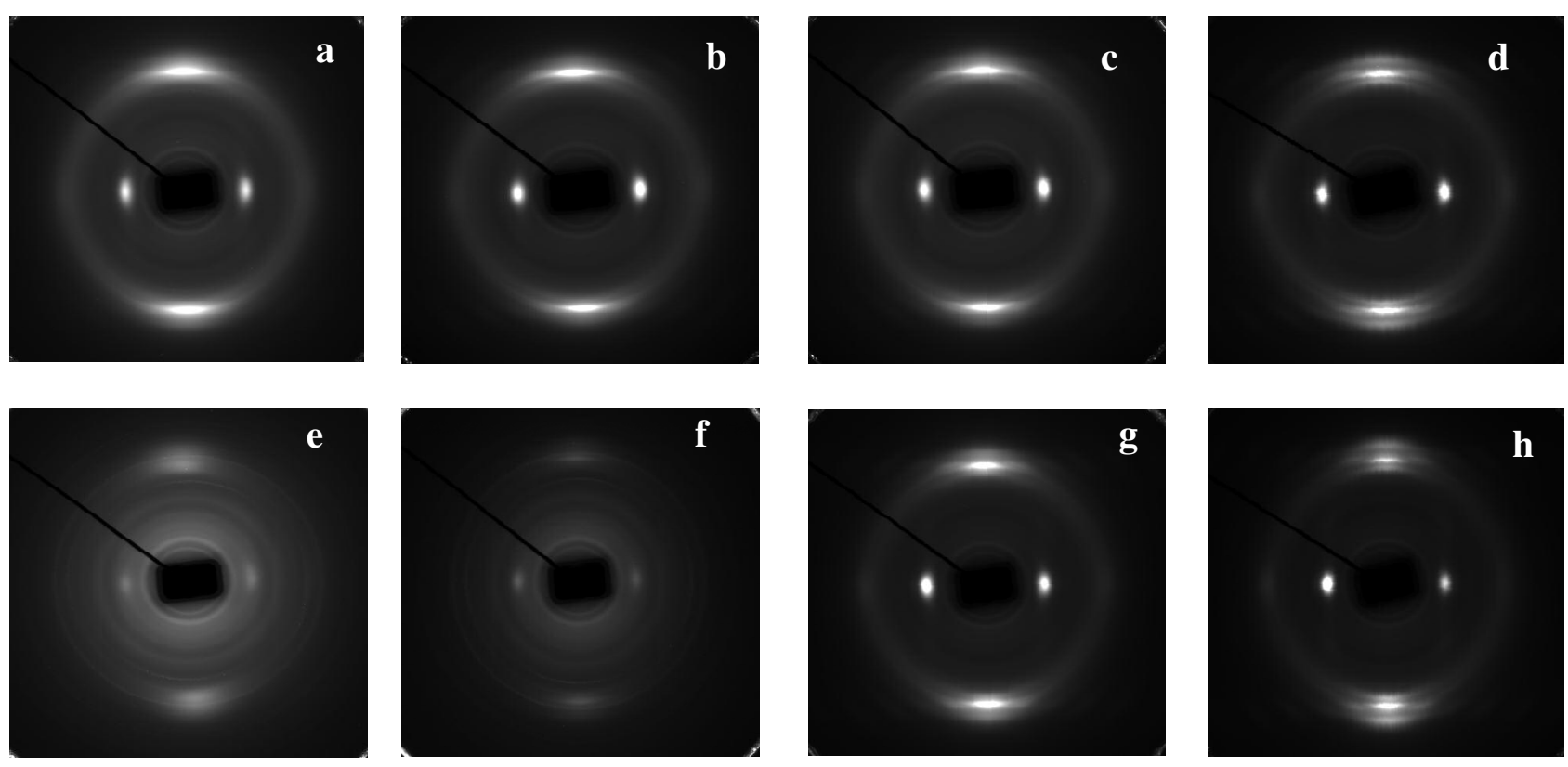


\section{Table 1.}

\begin{tabular}{|c|c|c|c|c|c|c|c|}
\hline $\begin{array}{l}\text { Sample/ } \\
\text { Annealing }\end{array}$ & $\begin{array}{c}\text { Young } \\
\text { modulus, } \\
\text { E, GPa }\end{array}$ & $\begin{array}{c}\text { Yield } \\
\text { Stress*, } \\
\sigma_{\mathrm{y}}, \mathrm{MPa}\end{array}$ & $\begin{array}{c}\text { Yield } \\
\text { Strain, } \\
\varepsilon_{\mathrm{y}}, \%\end{array}$ & $\begin{array}{c}\text { Max. } \\
\text { Stress, } \\
\sigma_{\text {max, }} \text { MPa }\end{array}$ & $\begin{array}{c}\text { Max. } \\
\text { Strain, } \\
\sigma_{\max }, \%\end{array}$ & $\begin{array}{c}\text { Stress at } \\
\text { break, } \\
\sigma_{\mathrm{br}}, \mathrm{MPa}\end{array}$ & $\begin{array}{c}\text { Strain at } \\
\text { break, } \\
\varepsilon_{\text {br }}, \%\end{array}$ \\
\hline $\begin{array}{l}\text { PA6 iso } \\
120^{\circ} \mathrm{C} / 1 \mathrm{~h}\end{array}$ & $\begin{array}{c}0.73 \\
\pm 0.02\end{array}$ & $42 \pm 2$ & $24 \pm 2$ & $44 \pm 3$ & $66 \pm 18$ & $17 \pm 8$ & $81 \pm 18$ \\
\hline $\begin{array}{l}\text { PA6 iso } \\
160^{\circ} \mathrm{C} / 1 \mathrm{~h}\end{array}$ & $\begin{array}{c}1,01 \\
\pm 0.04\end{array}$ & $47 \pm 2$ & $24 \pm 3$ & $47 \pm 4$ & $24 \pm 3$ & $30 \pm 14$ & $70 \pm 18$ \\
\hline $\begin{array}{l}\text { PA6 iso } \\
200^{\circ} \mathrm{C} / 1 \mathrm{~h}\end{array}$ & $\begin{array}{c}1.03 \\
\pm 0.04\end{array}$ & $51 \pm 2$ & $28 \pm 3$ & $51 \pm 2$ & $28 \pm 5$ & $41 \pm 12$ & $37 \pm 6$ \\
\hline $\begin{array}{l}\text { PA6 oc no } \\
\text { annealing }\end{array}$ & $\begin{array}{c}0.99 \\
\pm 0.04\end{array}$ & $\begin{array}{c}66 \pm 2 \\
123 \pm 2\end{array}$ & $42 \pm 14$ & $201 \pm 17$ & $149 \pm 26$ & $193 \pm 16$ & $150 \pm 68$ \\
\hline $\begin{array}{l}\text { PA6 oc } \\
120^{\circ} \mathrm{C} / 1 \mathrm{~h}\end{array}$ & $\begin{array}{c}1.78 \\
\pm 0.12\end{array}$ & $\begin{array}{c}88 \pm 1 \\
157 \pm 2\end{array}$ & $36 \pm 3$ & $169 \pm 19$ & $72 \pm 20$ & $169 \pm 19$ & $74 \pm 20$ \\
\hline $\begin{array}{l}\text { PA6 oc } \\
160^{\circ} \mathrm{C} / 1 \mathrm{~h}\end{array}$ & $\begin{array}{c}3.18 \\
\pm 0.14\end{array}$ & $\begin{array}{l}105 \pm 2 \\
170 \pm 3\end{array}$ & $28 \pm 5$ & $223 \pm 14$ & $62 \pm 13$ & $223 \pm 16$ & $64 \pm 14$ \\
\hline $\begin{array}{l}\text { PA6 oc } \\
200^{\circ} \mathrm{C} / 1 \mathrm{~h}\end{array}$ & $\begin{array}{r}3.78 \\
\pm 0.17\end{array}$ & $\begin{array}{l}103 \pm 3 \\
180 \pm 2\end{array}$ & $25 \pm 3$ & $185 \pm 9$ & $47 \pm 9$ & $185 \pm 9$ & $48 \pm 10$ \\
\hline
\end{tabular}


Table 2.

\begin{tabular}{|c|c|c|c|c|c|c|c|c|}
\hline $\begin{array}{c}\text { Sample/ } \\
\text { Annealing } \\
\text { temperature, } \\
{ }^{\mathbf{o}} \mathbf{C}\end{array}$ & $\begin{array}{c}\boldsymbol{\alpha}_{\mathbf{2 0 0}} \\
\mathbf{\%}\end{array}$ & $\begin{array}{c}\boldsymbol{\alpha}_{\mathbf{0 0 2}} / \mathbf{\alpha}_{\mathbf{2 0 2}} \\
\mathbf{\%}\end{array}$ & $\begin{array}{c}\mathbf{C I}_{\boldsymbol{\alpha}} \\
\mathbf{\%}\end{array}$ & $\begin{array}{c}\gamma_{001}, \\
\mathbf{\%}\end{array}$ & $\begin{array}{c}\boldsymbol{\gamma}_{\mathbf{2 0 0}} \\
\mathbf{\%}\end{array}$ & $\begin{array}{c}\mathbf{C I}_{\boldsymbol{\gamma}} \\
\mathbf{\%}\end{array}$ & $\begin{array}{c}\mathbf{C I}_{\text {Total }} \\
\text { or } \\
\mathbf{E C I}\end{array}$ & $\begin{array}{c}\boldsymbol{\alpha} / \boldsymbol{\gamma} \\
\mathbf{c o n t e n t}\end{array}$ \\
\hline $\begin{array}{c}\text { PA6 isotropic } \\
120^{\circ} \mathrm{C}-1 \mathrm{~h}\end{array}$ & 17 & 21 & 38 & 4 & 2 & 6 & 44 & 6.3 \\
\hline PA6 isotropic & 17 & 22. & 39 & 4 & 2 & 6.0 & 45 & 6.5 \\
$160^{\circ} \mathrm{C}-1 \mathrm{~h}$ & $(16)$ & $(25)$ & $(41)$ & $(5)$ & $(2)$ & $(7)$ & $(48)$ & $(6.0)$ \\
\hline PA6 isotropic & 14 & 23 & 37 & 4 & 2 & 7 & 44 & 5.3 \\
$200^{\circ} \mathrm{C}-1 \mathrm{~h}$ & $(12)$ & $(29)$ & $(41)$ & $(3)$ & $(4)$ & $(7)$ & $(48)$ & $(5.8)$ \\
\hline PA6 oriented & 5 & 7 & 12 & 24 & 9 & 33 & 45 & 0.4 \\
No annealing & $(15)$ & $(17)$ & $(32)$ & $(8)$ & $(8)$ & $(16)$ & $(48)$ & $(2.0)$ \\
\hline PA6 oriented & 17 & 13 & 30 & 2 & 17 & 20 & 50 & 1.5 \\
$120^{\circ} \mathrm{C}-1 \mathrm{~h}$ & $(18)$ & $(27)$ & $(44)$ & $(7)$ & $(2)$ & $(9)$ & $(53)$ & $(4.9)$ \\
\hline PA6 oriented & 17 & 25 & 42 & 4 & 2 & 6 & 48 & 7.0 \\
$160^{\circ} \mathrm{C}-1 \mathrm{~h}$ & $(11)$ & $(30)$ & $(40)$ & $(5)$ & $(1)$ & $(6)$ & $(46)$ & $(6.7)$ \\
\hline PA6 oriented & 16 & 20 & 36 & 4 & 10 & 14 & 50 & 2.6 \\
$200^{\circ} \mathrm{C}-1 \mathrm{~h}$ & $(11)$ & $(19)$ & $(30)$ & $(16)$ & $(9)$ & $(25)$ & $(55)$ & $(1.2)$ \\
\hline
\end{tabular}


Figure 3.

\begin{tabular}{|c|c|c|c|c|c|c|c|}
\hline & tealing of $1 \mathrm{~h}$ at & $L$ estir & $\operatorname{tes}^{\mathrm{a})}, \AA$ & $L_{c}$ & & & \\
\hline & & Before & After & Before & After & Before & After \\
\hline. & $120^{\circ} \mathrm{C}$ & $90-92$ & $71^{b)}$ & 67 & - & 25 & - \\
\hline$\stackrel{5}{0}$ & $160^{\circ} \mathrm{C}$ & $91-94$ & $97-98$ & 68 & 63 & 26 & 34 \\
\hline 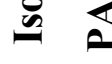 & $200^{\circ} \mathrm{C}$ & $101-105$ & $103-107$ & 67 & 64 & 36 & 41 \\
\hline & Without annealing & 68 & $-^{c)}$ & & & & \\
\hline$\sum_{1}^{0}$ & $100^{\circ} \mathrm{C}$ & 67 & -c) & & & & \\
\hline تِّ & $120^{\circ} \mathrm{C}$ & 66 & 70 & & & & \\
\hline ల & $160^{\circ} \mathrm{C}$ & 69 & 73 & & & & \\
\hline & $200^{\circ} \mathrm{C}$ & 88 & 82 & & & & \\
\hline
\end{tabular}


Figure 4.

\begin{tabular}{|c|c|c|c|c|c|c|c|c|c|c|c|}
\hline \multirow{2}{*}{\multicolumn{2}{|c|}{$\begin{array}{c}\text { Annealing of } 1 \mathrm{~h} \\
\text { at }\end{array}$}} & \multicolumn{2}{|c|}{$d \alpha_{200}$} & \multicolumn{2}{|c|}{$d \alpha_{002} / 202$} & \multicolumn{2}{|c|}{$d \gamma_{200}$} & \multicolumn{2}{|c|}{$d \gamma_{001}$} & \multicolumn{2}{|c|}{$d \gamma_{020}$} \\
\hline & & Before & After & Before & After & Before & After & Before & After & Before & After \\
\hline \multirow{3}{*}{ 葛 } & $120^{\circ} \mathrm{C}$ & 8.499 & 8.465 & 7.216 & 7.314 & 7.675 & 7.808 & 3.990 & 4.008 & - & - \\
\hline & $160^{\circ} \mathrm{C}$ & 8.522 & 8.566 & 7.197 & 7.187 & 7.682 & 7.649 & 4.011 & 4.002 & - & - \\
\hline & $200^{\circ} \mathrm{C}$ & 8.558 & 8.554 & 7.165 & 7.138 & 7.640 & 7.671 & 4.100 & 4.054 & - & - \\
\hline \multirow{4}{*}{ 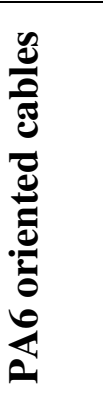 } & $\begin{array}{l}\text { Without } \\
\text { annealing }\end{array}$ & 8.610 & 8.453 & 7.467 & 7.544 & 7.800 & 7.828 & 4.080 & 4.105 & 16.858 & 15.300 \\
\hline & $120^{\circ} \mathrm{C}$ & 8.342 & 8.418 & 7.438 & 7.633 & 7.928 & 7.826 & 4.074 & 4.038 & 15.880 & 15.300 \\
\hline & $160^{\circ} \mathrm{C}$ & 8.522 & 8.566 & 7.197 & 7.187 & 7.682 & 7.649 & 4.011 & 4.002 & 16.028 & 14.640 \\
\hline & $200^{\circ} \mathrm{C}$ & 8.558 & 8.554 & 7.165 & 7.138 & 7.640 & 7.671 & 4.100 & 4.054 & 16.028 & 14.400 \\
\hline
\end{tabular}

